\title{
Design for Environment
}

\section{Janine Sekutowski}

Materials processing in the United States alone generates billions of pounds of hazardous waste each year in the form of solid wastes, discharges to water, or air emissions. As a result, environmental regulations are becoming increasingly stringent, severely limiting options for dealing with wastes. Complying with these regulations is not a matter of choice, nor is it inexpensive. Industry spends tens of billions of dollars for end-of-pipe pollution control.

Within industry and government there is a shift away from dealing with waste after the fact toward minimizing the generation of waste in the first place. The U.S. Environmental Protection Agency (EPA) has proposed a four-level hierarchy for waste management: source reduction, recycling, waste treatment, and waste disposal. The first two levels are concerned with minimizing waste, the latter two with end-ofpipe control.

Source reduction encompasses any activity that reduces or eliminates the generation of waste within a process. Examples of source reduction are materials substitution, process changes, and improved operating procedures. If waste cannot be avoided or reduced at the source, recycling options are to be explored to avoid the need to dispose of the waste. Only when source reduction and recycling are not possible is waste treatment and/or disposal to be contemplated. Waste disposal should be the option of last resort.

At AT\&T Bell Laboratories, we propose adding a level at the top of the EPA waste management hierarchy to create a fivelevel hierarchy. This level, called "design for environment (DFE)," will address environmental issues in the product concept and design stages, long before any waste is generated and the need for source reduction becomes apparent.

Decisions made during the design phase profoundly impact the entire life cycle of the product, from design through manufacturing, distribution, installation, servicing, and disposal. Many estimates say that from 80 to $90 \%$ of the total life cycle costs of a product are determined in the design phase. Integrating the design process with environmental engineering concerns will mitigate environmental problems downstream from the design phase, resulting in an overall reduction in costs associated with manufacturing process wastes.

AT\&T has put much effort into integrating the design process with other functions using the concept of DFX. DF stands for "design for" and X stands for "manufacturability, installability, reliability, safety, and other considerations beyond performance and functionality." ${ }^{1}$ DFE (design for environment) will take the DFX concept a step further, and will integrate design and environmental engineering to minimize the environmental impact of manufacturing as well as other downstream operations.

\section{Waste disposal should be the option of last resort.}

Several waste streams are associated with the life cycle of a product, starting with manufacture, and AT\&T is investigating the DFE approach to address these issues. For example, materials selection guidelines will be structured to help designers avoid specifying materials or processes that contribute to the volume or toxicity of the factory waste stream. Process design guidelines will help process designers assess the environmental soundness of a new manufacturing process or new equipment. The idea here is to make process designers think through the environmental ramifications of a new process before it is installed. Performing a material flow balance or waste audit on a process to make it as environmentally benign as possible can preempt expensive and intrusive fixes later on.

Frequently, a significant part of a factory's waste stream is packaging material from purchased supplies, components, and subassemblies. Guidelines for purchasing agents or those responsible for pre-approved component and preferred

1. D.A. Gatenby, G. Foo, "Design for X: Key to Competitive Profitable Markets," ATET Technical Journal 69 (3) (1990) p. 2-13. vendor selection would affect this particular waste stream. Vendors who don't overpackage their products or subassemblies and who ship their wares in easily recyclable packaging would be preferred. The same would be true for our product packaging. As a general rule, packaging materials should be biodegradable, recyclable, or safe for incineration. Furthermore, materials usage should be limited to no more than is absolutely necessary to achieve basic product protection.

Ultimately, DFE is a means to an end bigger than just the reduction of factory waste streams. During the design stage, environmental concerns associated with the front end (the supply chain) and the after-sale phase of the product life cycle can be addressed as well. It is this ability to influence the whole product life cycle that makes DFE such a potent concept-and much more than just a waste minimization approach. Besides, waste isn't the only environmental concern in materials processing. Energy efficiency and resource usage are other factors worth considering, and DFE is uniquely suited to address these and other issues.

Environmental issues pertaining to the back end (the after-sale phase) of the product life cycle have not received much attention up to now, and it is here that we may see the most sweeping changes. Sooner or later, all products either break down or become obsolete-they become waste products themselves. Traditional disposal options such as landfilling may not be available much longer, particularly since electronic products consist of many materials considered hazardous (i.e., lead in solder). This raises the possibility of having to design our products for safe disposal or recycling. Clearly this requires a revolutionary approach-a "design for recyclability" concept. A complex product can be designed for relatively effortless disassembly into various components and materials types for easy recycling.

A concept in its infancy, DFE has the potential to significantly impact types and quantities of waste. Done properly it can also minimize the environmental impact associated with a product's use and eventual disposal. It is a paradigm shift in managing waste because it aims to prevent pollution in the first place.

Janine Sekutowski is a supervisor in the Environmental and Materials Technology Department, ATET Bell Laboratories, Princeton, Newu Jersey. She co-chaired the 1991 MRS Spring Meeting symposium on environmentally conscious materials processing. 